\title{
Energy Efficiency Evaluation in Pumping System
}

\author{
Sharad P. Jagtap ${ }^{1}$, Anand N. Pawar ${ }^{2}$ \\ ${ }^{1}$ Mechanical Engineering Department, Government Polytechnic, Murtizapur, India \\ ${ }^{2}$ Mechanical Engineering Department, Government Polytechnic, Amravati, India \\ Email: jagtapsp@rediffmail.com, anp5000@gmail.com
}

Received September 12, 2013; revised October 19, 2013; accepted November 7, 2013

Copyright (C) 2013 Sharad P. Jagtap, Anand N. Pawar. This is an open access article distributed under the Creative Commons Attribution License, which permits unrestricted use, distribution, and reproduction in any medium, provided the original work is properly cited.

\begin{abstract}
Like 3M's (Man, Machine and Material), energy is one of the major inputs for economic development of the country. In case of developing countries like India, the energy sector assumes critical importance in the view of the ever increasing energy needs, requiring huge investments for new power plant erection. About $85 \%$ of total primary energy need comes from fossil fuels. Particularly, oil contributes to $31 \%$ primary energy sources and the existence of it from domestic source in India may last for only about 20 years only at the current reserve to production $(\mathrm{R} / \mathrm{P})$ ratio. Similarly, coal contributes to $54 \%$ primary energy sources and may last for about 114 years at the current reserve to production $(\mathrm{R} / \mathrm{P})$ ratio. Water Pumping System is one of the major utilities in SME's as well as power \& process industry, and consumes about 10\% - 15\% electrical power in Industrial and Agricultural sector. As per TERI Energy data directory yearbook, Industrial sector and Agricultural sector contribute to $45 \%$ and $7 \%$ of the total energy needed respectively in India. A measurable amount of Industrial production is delivered from small and medium industries operated with inefficient equipment, where it has been difficult to implement efficiency improvements. The objective of Water Pumping System in most cases is either to transfer liquid from one reservoir to another or to circulate liquid across the heat exchanger around a system. Since worldwide, centrifugal pumps account for the majority of electricity used by pumps, this paper focuses on energy saving in centrifugal pumping system with a case study work carried out in an industry.
\end{abstract}

Keywords: Energy Audit; Energy Saving; Pumping System; Performance Evaluation of Pumping System

\section{Introduction}

The pumps come in a various sizes for wide applications. It can be classified according to their operating principles as dynamic or displacement type. Dynamic pumps can be sub-classified as centrifugal and special effect pumps and Displacement pumps can be classified by rotary and reciprocating pumps. Out of all types of pumps, reciprocating pump is more energy efficient but increases maintenance cost, that's why worldwide, centrifugal pumps accounted for major electricity using equipment in palmping system [1].

Due to ever increasing in economic growth for developing countries, product variation and its production rate in process industry are continuously being changed; hence pump is dynamic device which is not delivered to the fixed volume of liquid as its pressure head changes. Therefore, to attain the best performance from pumping system, it is to be analyzed critically. Overall energy efficiency of plant would be achieved when energy inten- sity in a specific product, process or area of production or consumption is reduced without affecting output or comfort levels. Nowadays, such plant energy efficiency evaluation is carried out in "Energy Audit" projects.

\section{Energy Conservation}

Under the provisions of the Energy Conservation Act, 2001 The, Government of India setup Bureau of Energy Efficiency (BEE), a statutory body under the ministry of power on 1st March 2002, with the primary objective of reducing energy intensity of the Indian economy. This will be achieved with active participation of all stakeholders, resulting in accelerated and sustained adoption of energy efficiency in all sectors [2]. Pumping system is used in wide application in industry as well as agriculture sector. By the survey of few Energy Efficiency Projects in India, there are many ways for enhancing energy efficiency in pumping system which is directly depends on its operation philosophy and capacity uses. 
Energy efficiency study (Energy Audit) means the verification, monitoring and analysis of use of energy including submission of technical report containing recommendations for improving energy efficiency with cost benefit analysis and action plan to reduce energy consumption. Energy audit helps to understand more about the ways energy is used in the industry, and helps to identify the area where energy waste \& scope for improvement can occur. It is carried out by following way.

Preliminary Audit/Walk through audit: By using existing data (energy bills and invoices) and general observations through walk through, establishes energy consumption pattern and its baseline or reference point as well as identify areas for more detail study/measurements.

Targeted Energy Audit: It is often results from Preliminary EA and provides detail analysis of targeted project like pumping system, compressed air system, steam and boiler system, lighting system, etc.

Detail Energy Audit: It is comprehensive energy study of the plant constitute energy balance, detail measurement and calculations for performance evaluation of kind of systems in the plant. Identification of Energy Conservation Opportunities (ENCON), Cost benefit analysis and preparation of action plan for implementation of ENCON measures is carried out. After implementation of ENCON measures monitoring and periodic review also carried out [3].

Detail energy efficiency study of a chemical industry was carried out in India. In this paper energy efficiency analysis of chilled water pumping system for Vapor Absorption Machine (VAM) has analyzed. The total connected load of the entire plant was around $8700 \mathrm{~kW}$. Studied plant was a chemical industry therefore most of the processes energy load were critical (affects production) for power failure from electricity board hence power supply for such process were catered by two gas engines. Figure 1 shows the average electrical energy demand of

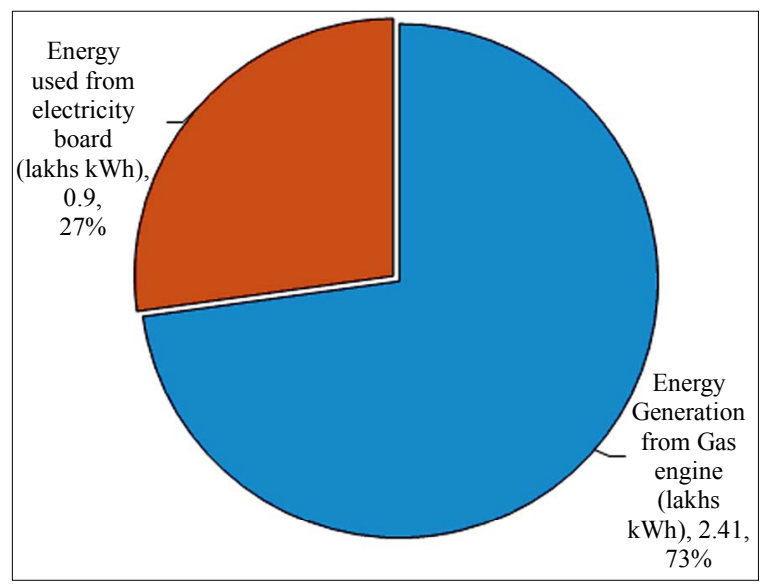

Figure 1. Total Energy Consumption of the Plant. entire plant. Energy generation per month for installed gas engines ware studied from history recorded, the average energy generation per month was 2.41 lakhs units $(\mathrm{kWh})$ and simultaneously energy bills from electricity board also analyzed which was shown average energy consumed per month was 0.9 lakhs units $(\mathrm{kWh})$.

\section{Energy Conservation in Chilled Water Pumping System of VAMs}

Performance analysis and finding of suitable measures for pumping system of VAM (Vapor Absorption Machine) is carried out as an actual case study work. Two nos. of hot water driven Vapor Absorption Machines were installed. Each VAM is dedicated with individual Gas Engine jacket heat. Both the VAM operations are as per plant demand. Radiator fans for Gas Engines were available to reject the heat from hot water when the chiller is not in operation. The installed lithium bromideWater pair VAM as shown in Figure 2 consists of five basic components as per following.

1) Generator: The purpose of the generator is to deliver the refrigerant vapor to the rest of the system. It accomplishes this by separating the water (refrigerant) from the lithium bromide-and-water solution. In the generator, a high-temperature energy source, hot water from diesel Engine jacket cooling flows through tubes that are immersed in a dilute solution of refrigerant and absorbent. The solution absorbs heat from the warmer water, causing the refrigerant to boil (vaporize) and separate from the absorbent solution ( $\mathrm{Li}-\mathrm{Br}$ ). As the refrigerant is boiled away, the absorbent solution becomes more concentrated. The concentrated absorbent solution returns to the absorber and the refrigerant vapor migrates to the condenser.

2) Condenser: The purpose of condenser is to condense the refrigerant vapors. Inside the condenser, cooling water flows through tubes and the hot refrigerant vapor fills the surrounding space. As heat transfers from

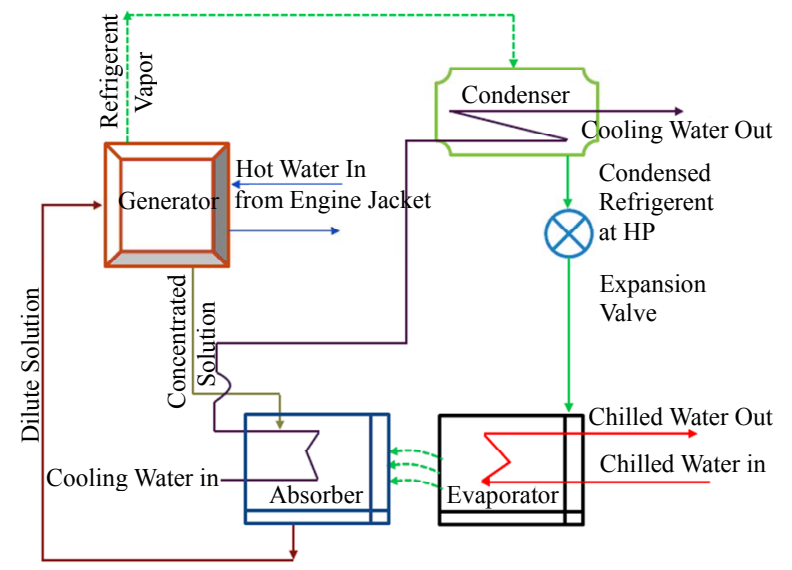

Figure 2. Components of VAM. 
the refrigerant vapor to the water, refrigerant condenses on the tube surfaces. The condensed liquid refrigerant collects in the bottom of the condenser before traveling to the expansion device. The cooling water system is typically connected to a cooling tower. Generally, the generator and condenser are contained inside of the same shell.

3) Expansion Valve: From the condenser, the liquid refrigerant flows through an expansion device into the evaporator. The expansion device is used to maintain the pressure difference between the high-pressure (condenser) and low-pressure (evaporator) sides of the refrigeration system by creating a liquid seal that separates the highpressure and low pressure sides of the cycle. As the highpressure liquid refrigerant flows through the expansion device, it causes a pressure drop that reduces the refrigerant pressure to that of the evaporator. This pressure reduction causes a small portion of the liquid refrigerant to boil off, cooling the remaining refrigerant to the desired evaporator temperature. The cooled mixture of liquid and vapor refrigerant then flows into the evaporator.

4) Evaporator: The purpose of evaporator is to cool the circulating water (Chilled water). The evaporator contains a bundle of tubes that carry the system water to be cooled/chilled. High pressure liquid condensate (refrigerant) is throttled down to the evaporator pressure (typically around $6.5 \mathrm{~mm} \mathrm{Hg}$ absolute). At this low pressure, the refrigerant absorbs heat from the circulating water and evaporates. The refrigerant vapors thus formed tend to increase the pressure in the vessel. This will in turn increase the boiling temperature and the desired cooling effect will not be obtained. So, it is necessary to remove the refrigerant vapors from the vessel into the lower pressure absorber. Physically, the evaporator and absorber are contained inside the same shell, allowing refrigerant vapors generated in the evaporator to migrate continuously to the absorber.

5) Absorber: Inside the absorber, the refrigerant vapor is absorbed by the lithium bromide solution. As the refrigerant vapor is absorbed, it condenses from a vapor to a liquid, releasing the heat it acquired in the evaporator. The absorption process creates a lower pressure within the absorber. This lower pressure, along with the absorbent's affinity for water, induces a continuous flow of refrigerant vapor from the evaporator. In addition, the absorption process condenses the refrigerant vapors and releases the heat removed from the evaporator by the refrigerant. The heat released from the condensation of refrigerant vapors and their absorption in the solution is removed to the cooling water that is circulated through the absorber tube bundle. As the concentrated solution absorbs more and more refrigerant; its absorption ability decreases. The weak absorbent solution is then pumped to the generator where heat is used to drive off the re- frigerant. The hot refrigerant vapors created in the generator migrate to the condenser. The cooling tower water circulating through the condenser turns the refrigerant vapors to a liquid state and picks up the heat of condensation, which it rejects to the cooling tower. The liquid refrigerant returns to the evaporator and completes the cycle.

Figure 3 shows the chilled water pumping arrangement of VAMs. Primary chilled water pumps were transferring water from primary chilled water storage to evaporator of VAMs and get more chilled and stored it in secondary chilled water storage, from where secondary chilled water pumps transfer it to plant departments.

At most of the plants facility, it was observed that without understanding the correct pressure drop in pumping system causes oversized selection of pumps, resulting into running of pumps far away from duty point (best efficiency point). Thus due to dynamic flow-head-efficiency characteristics of centrifugal pumps, leads to substantial drop in operating efficiency. Besides, worn-out parts and increased clearances over the period of time also cause de rating in operating efficiency. As a thumb rule, operating cost of a centrifugal pump is approximately 15 times higher than the initial cost. Due to these reasons, study of pumping system generally offers maximum energy saving potential with attractive payback.

Theoretically capacity requirement for present pumping system is analyzed i.e. actual required volume of pumping water $\left(\mathrm{m}^{3} / \mathrm{hr}\right)$ with respective to required task (i.e. energy load of heat exchanger, evaporator) and pressure head $(\mathrm{m})$ through its elevation from pump reference. This theoretical study helped to compare the actual system parameters of pumping system. Pump always de-

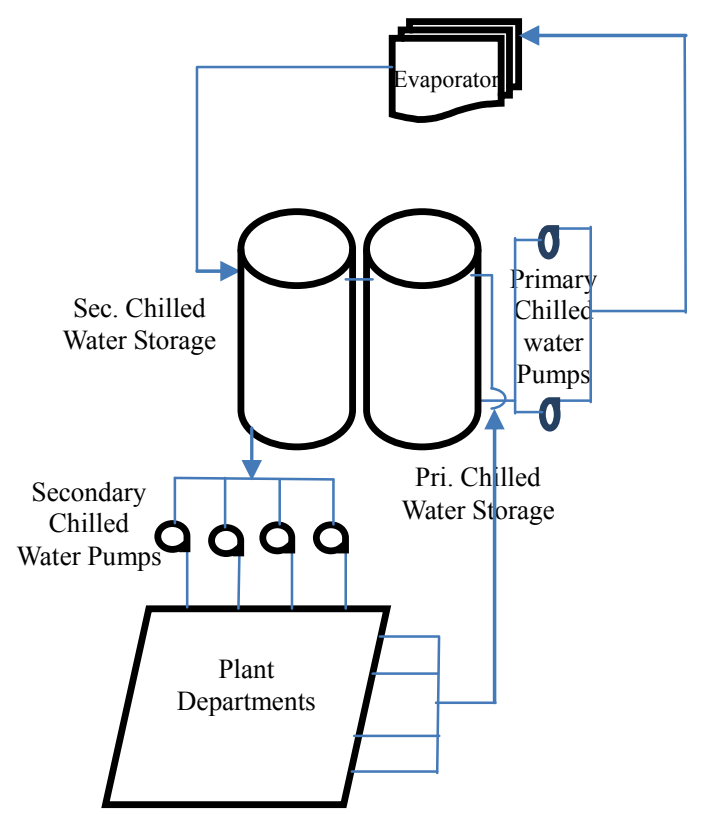

Figure 3. Chilled water pumping arrangement. 
signs at certain operating point (flow rate in $\mathrm{m}^{3} / \mathrm{hr}$ and pressure head in meter) at which if it is operated, gives maximum energy efficiency. Theoretical required pressure head study based on

- Desired volume $\left(\mathrm{m}^{3} / \mathrm{Hr}\right)$ of liquid

- It static head (Delivery elevation from reference of Pump)

- Dynamic head (Constitute Major and Minor pressure Losses)

Major dynamic pressure head losses are the friction loss in length of pipe line and pressure loss across the equipment (heat exchanger, surface condensers, evaporators, etc.) and minor dynamic pressure losses are caused by fittings, bends, valves, etc.

Objectives of the work: The major objective of the study is summarized hereunder.

- Performance evaluation of process cooling water pumping system

- Identification of Energy Conservation Opportunities (ENCON)

Operating Philosophy of Primary chilled water pumping system:

When both the VAMs are in operation, a higher head primary chilled water pump (MEGA-G-50-250) was running while smaller head primary chilled pump (MEGAG-50-160) is running when only one VAM is under operation. Separate secondary chilled pumps are installed for individual section where chilled water is demanded.

\subsection{Installation Details}

Specifications of hot water driven (from gas engine jacket cooling) of both VAM in the plant were as per Table 1.

As per chilled water arrangement shown in Figure 3, there were two separate pumping water network (primary and secondary). The installation details are shown in Table 2.

For performance analysis of chilled water $\&$ hot water pumps and capacity measurement of VAMs, the simultaneous measurements of water flow, pressure, power of respective pump and temperature at various points of VAMs is carried out by using ultra-sonic flow meter, digital pressure gauge, three phase load analyzer and digital temperature meter respectively.

\subsection{Performance Analysis and Recommendations for VAMs}

Performance analysis of VAM-I: Basic analogy for heat exchangers analysis is used by referring [4] and the actual measurements and performance evaluation for different parameters for VAM-I was carried out is shown in Table 3.

Performance analysis of VAM-II: Similarly actual measurements and performance evaluation for different

Table 1. Design details for VAM's.

\begin{tabular}{cc}
\hline Make & Thermax \\
\hline Model & B511S \\
Capacity $(\mathrm{TR})$ & 95 \\
Refrigerant & 0.66 \\
Nos. & Water \\
Design chilled water flow $\left(\mathrm{m}^{3} / \mathrm{hr}\right)$ & 2 \\
Design chilled water in/out temperature $\left({ }^{\circ} \mathrm{C}\right)$ & $12 / 7$ \\
Design Chilled water pressure drop $\left(\mathrm{Kg} / \mathrm{cm}^{2}\right)$ & 1 \\
Design cooling water flow $\left(\mathrm{m}^{3} / \mathrm{hr}\right)$ & 168 \\
Design cooling water in/out temperature $\left({ }^{\circ} \mathrm{C}\right)$ & $32 / 36.2$ \\
Design Cooling water pressure drop $\left(\mathrm{Kg} / \mathrm{cm}^{2}\right)$ & 1 \\
Design Hot Water flow $\left(\mathrm{m}^{3} / \mathrm{hr}\right)$ & 44 \\
Design hot water in/out temperature $\left({ }^{\circ} \mathrm{C}\right)$ & $88 / 78$ \\
\hline
\end{tabular}

Table 2. Design details for Chilled water pumps.

\begin{tabular}{|c|c|c|c|c|c|c|c|}
\hline \multicolumn{8}{|c|}{ Primary Chilled water pumps: 02 nos. } \\
\hline S.N. & Particular & Make & Type/Model & Flow $\left(\mathbf{m}^{3} / \mathbf{h r}\right)$ & Head (m) & Motor (KW) & Speed (rpm) \\
\hline \multirow{3}{*}{1} & & KSB & MEGA-G-50-250 & 60 & 60 & 22 & 2945 \\
\hline & Primary Pumps & & & & & & \\
\hline & & KSB & MEGA-G-50-160 & 60 & 32 & 7.5 & 2880 \\
\hline \multicolumn{8}{|c|}{ Secondary Chilled water pumps: 04 nos. } \\
\hline 1 & Secondary Pump-A & Beacon & $50 / 160$ & 30 & 40 & 7.5 & 2900 \\
\hline 2 & Secondary Pump-B & Beacon & $50 / 160$ & 50 & 35 & 7.5 & 2865 \\
\hline 3 & Secondary Pump-C & Beacon & $50 / 160$ & 30 & 40 & 7.5 & 2900 \\
\hline 4 & Secondary Pump-D & Kirloskar & DB $50 / 20$ & 60 & 43 & 15 & 2900 \\
\hline
\end{tabular}


parameters for VAM-II was carried out is shown in Table 4 .

Recommendation for both the VAMs: As per Tables 3 and 4, both the VAM's heat input were less compared to design level as shown in Figure 4. Similarly it was also observed that refrigeration effect of both the VAM's was less to their design. Hence the Co-efficient of Performance (COP) of both VAMs-I and VAM-II is reduced to expected design value of 0.66 as shown in Figure 5. Therefore it was recommended to clean the hot water and cooling water heat exchangers of both the VAMs to improve the heat input rate $(\mathrm{H} 1)$ and refrigera-

Table 3. Performance analysis of VAM-I.

\begin{tabular}{|c|c|c|c|}
\hline Chilled water flow $\left(\mathrm{m}^{3} / \mathrm{Hr}\right.$.) & 43.7 & \multicolumn{2}{|c|}{ Difference } \\
\hline Chilled water temp. diff. $\left({ }^{\circ} \mathrm{C}\right)$ & 12.2 & 7.4 & 4.8 \\
\hline Chilled water pressure drop $\left(\mathrm{kg} / \mathrm{cm}^{2}\right)$ & 2.8 & 1.6 & 1.2 \\
\hline Cooling water flow $\left(\mathrm{m}^{3} / \mathrm{Hr}\right.$.) & & 135 & \\
\hline Cooling water temp. diff. $\left({ }^{\circ} \mathrm{C}\right)$ & 29.2 & 32.9 & 3.7 \\
\hline Cooling water pressure drop $\left(\mathrm{kg} / \mathrm{cm}^{2}\right)$ & 1.4 & 0.5 & 0.9 \\
\hline Hot water flow (m³/Hr.) & & 50 & \\
\hline Hot water temp. diff. $\left({ }^{\circ} \mathrm{C}\right)$ & 78.5 & 71.7 & 6.8 \\
\hline Hot water pressure drop $\left(\mathrm{kg} / \mathrm{cm}^{2}\right)$ & 2.2 & 1.6 & 0.6 \\
\hline Actual Capacity (TR) & & 69.37 & \\
\hline Heat Input: H1 (Kcal/Hr.) & & 340,000 & \\
\hline Heat absorbed through chilled water : H2 (Kcal/Hr.) & & 209,760 & \\
\hline COP & & 0.62 & \\
\hline
\end{tabular}

Table 4. Performance analysis of VAM-II.

\begin{tabular}{|c|c|c|c|}
\hline Chilled water flow ( $\mathrm{m}^{3} / \mathrm{Hr}$.) & 42 & \multicolumn{2}{|c|}{ Difference } \\
\hline Chilled water temp. diff. $\left({ }^{\circ} \mathrm{C}\right)$ & 14.7 & 9.5 & 5.2 \\
\hline Chilled water pressure drop $\left(\mathrm{kg} / \mathrm{cm}^{2}\right)$ & 2.5 & 1.3 & 1.2 \\
\hline Cooling water flow $\left(\mathrm{m}^{3} / \mathrm{Hr}\right.$.) & \multicolumn{3}{|c|}{125} \\
\hline Cooling water temp. diff. $\left({ }^{\circ} \mathrm{C}\right)$ & 28.2 & 31 & 3.7 \\
\hline Cooling water pressure drop $\left(\mathrm{kg} / \mathrm{cm}^{2}\right)$ & 1.0 & 0.4 & 0.6 \\
\hline Hot water flow $\left(\mathrm{m}^{3} / \mathrm{Hr}.\right)$ & \multicolumn{3}{|c|}{54} \\
\hline Hot water temp. diff. $\left({ }^{\circ} \mathrm{C}\right)$ & 73.6 & 67 & 6.6 \\
\hline Hot water pressure drop $\left(\mathrm{kg} / \mathrm{cm}^{2}\right)$ & 2.4 & 1.0 & 1.4 \\
\hline Actual Capacity (TR) & \multicolumn{3}{|c|}{72.22} \\
\hline Heat Input : H1 (Kcal/Hr.) & \multicolumn{3}{|c|}{356,400} \\
\hline Heat absorbed through chilled water: H2 (Kcal/Hr.) & \multicolumn{3}{|c|}{218,400} \\
\hline COP & \multicolumn{3}{|c|}{0.61} \\
\hline
\end{tabular}

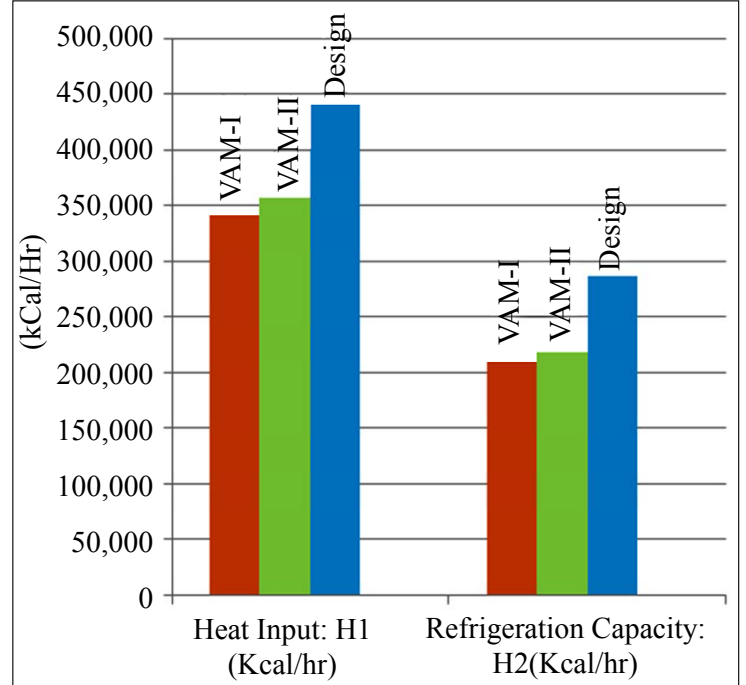

Figure 4. Heat rate analysis for both VAMs.

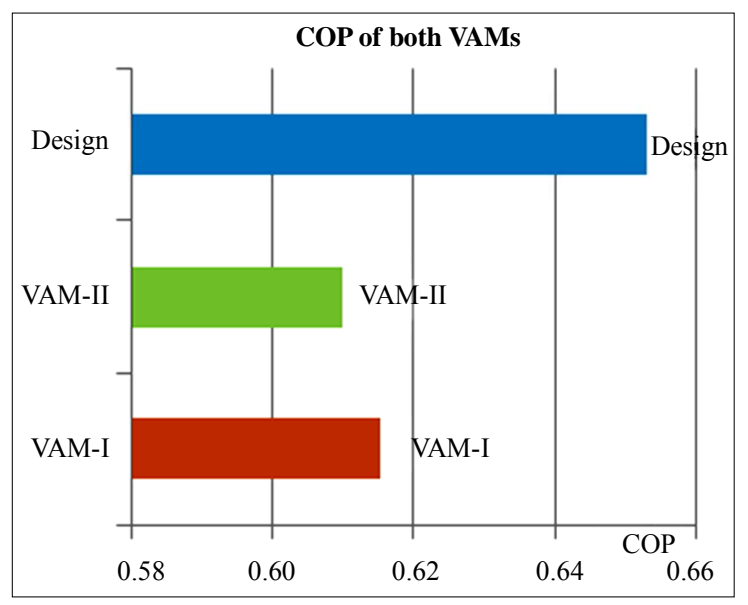

Figure 5. Comparison of actual COP with design COP.

tion Capacity (H2), and hence consequently the COP of both VAMs would be improved.

\subsection{Performance Analysis and Recommendations for Chilled Water Pumps}

\subsubsection{Performance Analysis and Recommendations for Primary Chilled Water Pumps}

With the help of ultrasonic flow meter and digital pressure gauge and electrical power analyzer chilled water flow rate $\left(\mathrm{m}^{3} / \mathrm{Hr}\right.$.), pressure $(\mathrm{m})$ and electrical power $(\mathrm{kW})$ respectively were measured. The measured values are plotted in following Table 5.

Two pumps of same flow rate $\left(60 \mathrm{~m}^{3} / \mathrm{Hr}\right)$ but different design pressure head $(60 \mathrm{~m}$ and $32 \mathrm{~m})$ were installed. The higher pressure head pump was used when both the VAMs were in operation for catering chilled water circulation in evaporators of both VAMs. The necessary pressure head, flow rate and their electrical power con- 
sumption were measured with the help of respective measuring instrument and summarized in Table 5.

During site survey and taking measurements, it was observed that, when low design head Primary Chilled Water pump (MEGA-G-50-160) in operation, the primary pump discharge pressure at $43 \mathrm{~m}^{3} / \mathrm{Hr}$ flows is $33 \mathrm{~m}$ and the pressure at the inlet of VAM m/c is $28 \mathrm{~m}$, which indicated $6 \mathrm{~m}$ of pressure drop in supply line. Similar was the case observed with high design head capacity pump operation (MEGA-G-50-250 as per operating philosophy of VAM), When both the chillers are in operation, the primary pump discharge pressure at capacity of $56 \mathrm{~m}^{3} / \mathrm{hr}$ indicated $10 \mathrm{~m}$ of pressure drop in supply line. This was also counterchecked with existing $100 \mathrm{~mm}$ diameter pipe and proposed retrofitted $150 \mathrm{~mm}$ diameter pipe with the help of Hazen-Williams Formula [5] as shown in Table 6.

$\mathrm{Hd}=[6.1961 \times 103 \times(\mathrm{Q} \times \delta / 60) 1.852] /[100 \times \mathrm{C} 1.852$

$\times$ Dh 4.87]

Where,

Hd Pressure head drop (m)

C Design coefficient determined for the type of pipe or tube - the higher the factor, the smoother the pipe or tube

Q Flow rate $\left(\mathrm{m}^{3} / \mathrm{Hr}\right)$

$\delta \quad$ Density of liquid (for Water $-1000 \mathrm{~kg} / \mathrm{m}^{3}$ )

$\mathrm{Dh} \quad$ Inside hydraulic diameter ( $\mathrm{mm})$

From the analysis of Pressure head loss for $100 \mathrm{~mm}$ and $150 \mathrm{~mm}$ diameter pipeline of Primary chilled water pumping system as shown in Figure 6, It was recom-

Table 5. Actual Measurements and performance evaluation for Primary Chilled Water Pumps.

\begin{tabular}{cccccc}
\hline S.N. & Pump no. & $\begin{array}{c}\text { Capacity } \\
\left(\mathbf{m}^{3} / \mathbf{h r}\right)\end{array}$ & $\begin{array}{c}\text { Total Head } \\
(\mathbf{m})\end{array}$ & $\begin{array}{c}\text { Power } \\
\mathbf{( k W )}\end{array}$ & $\begin{array}{c}\text { Efficiency } \\
(\mathbf{\%})\end{array}$ \\
\hline 1 & MEGA-G-50-250 & 56.2 & 66 & 20.9 & $56.9^{*}$ \\
2 & MEGA-G-50-160 & 43.7 & 33 & 8.12 & 56.9 \\
\hline
\end{tabular}

*Efficiency $=$ Total Head $(\mathrm{m}) \times$ Flow rate $\left(\mathrm{m}^{3} / \mathrm{hr}\right) /\{367 \times$ Eff.Motor $\times$ Input Electrical Power $(\mathrm{kW})\}$.

Table 6. Pressure Head loss evaluation for different diameter pipeline.

\begin{tabular}{ccc}
\hline Particular & $\begin{array}{c}\text { Low design } \\
\text { head pump }\end{array}$ & $\begin{array}{c}\text { Higher design } \\
\text { head pump }\end{array}$ \\
\hline Length of pipe line $(\mathrm{m})$ & 140 & 140 \\
Flow in pipe line $\left(\mathrm{m}^{3} / \mathrm{hr}\right)$ & 43 & 56 \\
Pipe line diameter $(\mathrm{mm})$ & 150 & 150 \\
Friction factor $(. \mathrm{C})($ Refer Annexure-I) & 100 & 100 \\
$\begin{array}{c}\text { Press. Head Loss when } 100 \mathrm{~mm} \\
\text { pipe diameter }(\mathrm{m}) \text { line }(\mathrm{mm})\end{array}$ & 6.058 & 9.880 \\
$\begin{array}{c}\text { Press. Head Loss when } 150 \mathrm{~mm} \\
\text { pipe diameter }(\mathrm{m}) \text { line }(\mathrm{mm})\end{array}$ & 0.84 & 1.37 \\
\hline
\end{tabular}

mended laying of $150 \mathrm{~mm}$ diameter pipeline (instead of $100 \mathrm{~mm}$ installed) with insulation. Also it was recommended to replace of both primary pumps with following rating.

Desired pressure head losses in pipeline after retrofitting of correct sized pipeline laying:

Desired total head: (Static Head) + (Chilled water pressure drop in evaporator) + (Discharge line friction $)+$ (\#Minor Losses)

(\# Minor pressure head losses were very less compares to other components in present VAM system, hence neglected.)

Proposed pump specification and power Consumption for MEGA-G-50-160 model

\begin{tabular}{cc}
\hline Static head & $: 5 \mathrm{~m}$ \\
\hline $\begin{array}{c}\text { Chilled water pressure drop in evaporator } \\
\text { for small pump operation }\end{array}$ & $: 12 \mathrm{~m}$ \\
Discharge line friction for small pump & $: 1 \mathrm{~m}$ \\
Total Pressure head for Small pump & $: 18 \mathrm{~m}$ \\
Required Capacity as per VAM & $: 45 \mathrm{~m}^{3} / \mathrm{Hr}$ \\
Efficiency (from market survey) & $: 72 \%$ \\
Assume Electrical Motor Eff. & $: 85 \%$ \\
Power consumption for above pump & $: 3.61 \mathrm{~kW}$
\end{tabular}

Proposed pump specification and power Consumption for MEGA-G-50-250 model

$\begin{array}{lc}\text { Total Pressure head for Big pump } & : 36 \mathrm{~m} \\ \text { Required Capacity as per VAM } & : 90 \mathrm{~m}^{3} / \mathrm{Hr} \\ \text { Efficiency (from market survey) } & : 78 \%\end{array}$

(Refer Annexure-II)

Power consumption for above pump

Existing power consumption $:(20.9+8.12) / 2^{*}$

$$
\text { : } 14.51 \mathrm{~kW}
$$

*For calculation of saving potential, single VAM and two VAM's operation at a time is considered $50 \%-50 \%$ as per operation history.

Proposed power consumption $:(3.61+13.32) / 2$

$: 8.46 \mathrm{~kW}$

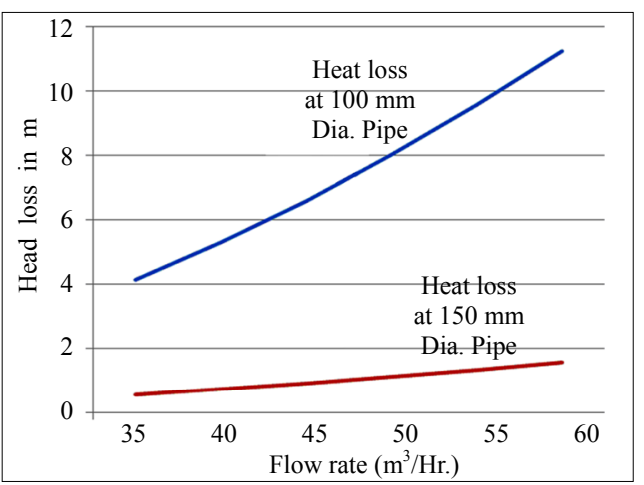

Figure 6. Analysis of Head Loss in pipeline. 


\subsubsection{Performance Analysis and Recommendations for Secondary Chilled Water Pumps}

With the help of measuring instruments, actual parameters of secondary chilled water pumps are measured and analysis for its performance was carried out as shown in Table 7.

From above analysis, it is clear that the efficiencies of Secondary Pump-A \& Secondary Pump -B are very poor and recommended to replace with energy efficient new pump. Hence it was recommended to replace the existing pump with following proposed rating.

$\begin{array}{ll}\text { Secondary pump-A: } & \\ \text { Capacity }\left(\mathrm{m}^{3} / \mathrm{hr}\right) & 15 \\ \text { Pressure }(\mathrm{m}) & 45 \\ \text { Efficiency }(\%) & 55 \\ \text { Proposed power consumption }(\mathrm{kW}): & 3.93 \\ \text { Secondary pump-B: } & \\ \text { Capacity }\left(\mathrm{m}^{3} / \mathrm{hr}\right) & 65 \\ \text { Pressure }(\mathrm{m}) & 22 \\ \text { Efficiency }(\%) & 77 \\ \text { Proposed power consumption }(\mathrm{kWh}) \text { : } & 5.95 \\ \text { Proposed power consumption in Secondary chilled } \\ \text { water pumps }=\mathbf{3 . 9 3}+\mathbf{5 . 9 5}+\mathbf{6 . 2}+\mathbf{1 0 . 4} \\ \quad=\mathbf{2 6 . 4 8} \mathbf{k W}\end{array}$

\subsubsection{Cost-Benefit Analysis}

Overall analysis of power consumption reduction was carried out by comparing existing and proposed measures for both primary and secondary chilled water system which is summarized in Table 8. Overall about $21 \%$ powers could be reduced by proposed measures as shown in Table 8.

$\begin{array}{ll}\text { Operational hours per day: } & 16 \\ \text { Operating days per annum: } & 350 \\ \text { Total operating hours per annum: } & 5600 \\ \text { Energy cost (Rs./kWh): } & 6.25 \\ \text { Energy Saving potential (Rs./year): } & 321,650 \\ \text { Tentative Investment (Rs.): } & 450,000 \\ \text { Payback (months): } & 17\end{array}$

Table 7. Actual Measurements and performance evaluation for Secondary Chilled Water Pumps.

\begin{tabular}{ccccccc}
\hline S.N. & Particular & $\begin{array}{c}\text { Pump } \\
\text { Identity }\end{array}$ & $\begin{array}{c}\text { Capacity } \\
\left(\mathrm{m}^{3} / \mathrm{Hr}\right)\end{array}$ & $\begin{array}{c}\text { Total } \\
\text { Head }(\mathrm{m})\end{array}$ & $\begin{array}{c}\text { Power } \\
(\mathrm{kW})\end{array}$ & $\begin{array}{c}\text { Efficiency } \\
(\%)\end{array}$ \\
\hline 1 & $\begin{array}{c}\text { Secondary } \\
\text { Pump-A }\end{array}$ & PA-639B & 13.4 & 41 & 5 & 35.2 \\
2 & $\begin{array}{c}\text { Secondary } \\
\text { Pump-B }\end{array}$ & PA-638A & 60.3 & 19 & 8.02 & 45.8 \\
3 & $\begin{array}{c}\text { Secondary } \\
\text { Pump-C }\end{array}$ & PA-637B & 37 & 33 & 6.2 & 63.1 \\
4 & $\begin{array}{c}\text { Secondary } \\
\text { Pump-D }\end{array}$ & PA-634A & 38 & 52 & 10.4 & 60.9 \\
\hline
\end{tabular}

Table 8. Power consumption reduction in Chilled water system.

\begin{tabular}{cccccc}
\hline S.N. & Pump & $\begin{array}{c}\text { Existing } \\
\text { Power }(\mathrm{kW})\end{array}$ & $\begin{array}{c}\text { Proposed } \\
\text { Power }(\mathrm{kW})\end{array}$ & $\begin{array}{c}\text { Power Saving } \\
(\mathrm{kWh})\end{array}$ & $\begin{array}{c}\text { Power } \\
\text { Saving (\%) }\end{array}$ \\
\hline 1 & $\begin{array}{c}\text { Primary } \\
\text { Chilled water }\end{array}$ & 14.51 & 8.46 & 6.05 & \\
2 & $\begin{array}{c}\text { Secondary } \\
\text { Chilled water }\end{array}$ & 29.62 & 26.48 & 3.14 & 20.82 \\
& Total & 44.13 & 34.94 & 9.19 \\
\hline
\end{tabular}

\section{Result and Discussion}

Through detail study, performance analysis of chilled water pumping system for VAMs of the industry was indicating remarkable saving opportunities in installed pumps. Installed primary and secondary chilled water pumps were not selected at proper duty point and also pipe diameter design in pipeline network was undersized. Overall chilled water pumping system consumes 44.13 $\mathrm{kWh}$ electrical units while that of proposed pumps would consume only 34.94 electrical units. Almost 21\% electrical power could be saved. Also in VAMs observation, the pressure drop across the evaporator is $1.2 \mathrm{~kg} / \mathrm{cm}^{2}$ compares to manufacturers design it should be $1.0 \mathrm{~kg} /$ $\mathrm{cm}^{2}$. This indicates evaporator tubes to maintain cleaned periodically.

\section{Conclusion}

The present study is honestly tried elaborate effort to examine the performance of a pumping system of VAM of a chemical industry. Energy audit as per Energy Conservation Act 2002 is an effective tool in identifying and perusing a comprehensive energy management program. A systematic approach to comprehensive understanding of any type of industry with their different processes can give the industry a plan with which it can effectively manage the industrial energy with its minimum cost. This approach could be useful for an industry in combating essential energy cost and also tapping many other benefits like improved production cost, higher profit and most important satisfaction for contributing in world energy saving.

\section{REFERENCES}

[1] Bureau of Energy Efficiency, "General Aspects of Energy Management and Energy Audit," Guide Books-01.

[2] Bureau of Energy Efficiency, "Energy Efficiency in Electrical Utilities" Guide Books-03, Chapter-01,02, Chapter-06,04.

[3] N. R. Kumbhar and R. R. Joshi, "An Industrial Energy Auditing: Basic Approach," International Journal of Modern Engineering Research (IJMER), Vol. 2, No.1, pp. 313-315. 
[4] Çengel Y.A. and Boles M.A., "The Second Law of Thermodynamics," In: Thermodynamics an Engineering Approach, 7th Edition, Chapter No. 06, McGraw Hill Com-

[5] S. W. Bedford, "Fluid Mechanics," 9th Edition, Tata panies Publication Book, New York. McGraw Hill Edu. Pvt. Ltd., New Delhi. 


\section{Annexure-I}

Table. Hazen-Williams's coefficients.

\begin{tabular}{|c|c|c|}
\hline \multirow{2}{*}{ Pipe Material } & \multicolumn{2}{|c|}{ Recommended C Value } \\
\hline & NewPipes@ & Design Purpose \\
\hline \multicolumn{3}{|l|}{ Unlined Metallic Pipes } \\
\hline Cast Iron, Ductile Iron & 130 & 100 \\
\hline Mild Steel & 140 & 100 \\
\hline Galvanized Iron above $50 \mathrm{~mm}$ dia. $^{\#}$ & 120 & 100 \\
\hline Galvanized Iron $50 \mathrm{~mm}$ dia and below used for house service connections. ${ }^{\#}$ & 120 & 55 \\
\hline \multicolumn{3}{|l|}{ Centrifugally Lined Metallic } \\
\hline Cast Iron, Ductile Iron and Mild Steel Pipes lined with cement mortar or Epoxy Up to $12,000 \mathrm{~mm}$ dia & 140 & 140 \\
\hline Above 1200 & 145 & 145 \\
\hline \multicolumn{3}{|l|}{ Projection Methose Cement Mortar Lined Metallic Pipes } \\
\hline Car Cast Iron, Ductile Iron and Mild Steel Pipes & $130^{*}$ & $110^{* *}$ \\
\hline \multicolumn{3}{|l|}{ Non Metallic Pipes } \\
\hline \multicolumn{3}{|l|}{ RCC Spun Concrete } \\
\hline \multicolumn{3}{|l|}{ Pre stressed Concrete } \\
\hline Up to $1200 \mathrm{~mm}$ dia & 140 & 140 \\
\hline Above $1200 \mathrm{~mm}$ dia & 145 & 145 \\
\hline Asbestos Cement & 150 & 140 \\
\hline PVC, GRP and other Plastic Pipes. & 150 & 145 \\
\hline
\end{tabular}

Note: $@$ The $\mathrm{C}$ values for new pipes included in the Table 6.1 are for determining the acceptability of surface finish of new pipelines. The user agency may specify that flow test may be conducted for determining the $\mathrm{C}$ value of laid pipelines. "the quality of galvanizing should be in accordance with the relevant standards to ensure resistance to corrosion throughout its design life. * For pipes of diameter $500 \mathrm{~mm}$ and above; the range of $\mathrm{C}$ values may be from 90 to 125 for pipes less than $500 \mathrm{~mm} .{ }^{* *}$ In the absence of specific data, this value is recommended. However, in case authentic field data is available, higher values up to 130 may be adopted.

\section{Annexure-II}

\begin{tabular}{|c|c|c|c|}
\hline \multicolumn{4}{|c|}{ Pump performance Data sheet } \\
\hline Customer & $:$ & Quote Number & $:$ \\
\hline Item No & $: 02$ & Stage & $: 01$ \\
\hline Uses Territory & $:$ & Based on Curve No & : HD18811CAD Rev 1 \\
\hline Quantity & $: 01$ & Date Last Saved & : 10 May 2011, 7:07 AM \\
\hline \multicolumn{2}{|c|}{ Operation Conditions } & \multicolumn{2}{|c|}{ Liquid } \\
\hline Flow Rated & $: 75.00 \mathrm{~m}^{3} / \mathrm{Hr}$ & Liquid Type & $:$ \\
\hline Differential Head/Pressure Rated (required) & $: 35 \mathrm{~m}$ & Additional liquid description & : Water \\
\hline Differential Head/Pressure Rated (actual) & $: 35.1 \mathrm{~m}$ & Solids diameter Max. & $: 0.00 \mathrm{~mm}$ \\
\hline Suction pressure rated/Max & $: 0.00 / 0.00$ bar $\mathrm{g}$ & Temperature Max. & $: 20.00 \operatorname{deg} \mathrm{C}$ \\
\hline NPSH available, rated & : Ample & Fluid density rated/Max & $: 1.000 / 1.000 \mathrm{SG}$ \\
\hline Frequency & $: 50 \mathrm{~Hz}$ & Viscosity rated & $: 1.00 \mathrm{cST}$ \\
\hline
\end{tabular}




\section{Continued}

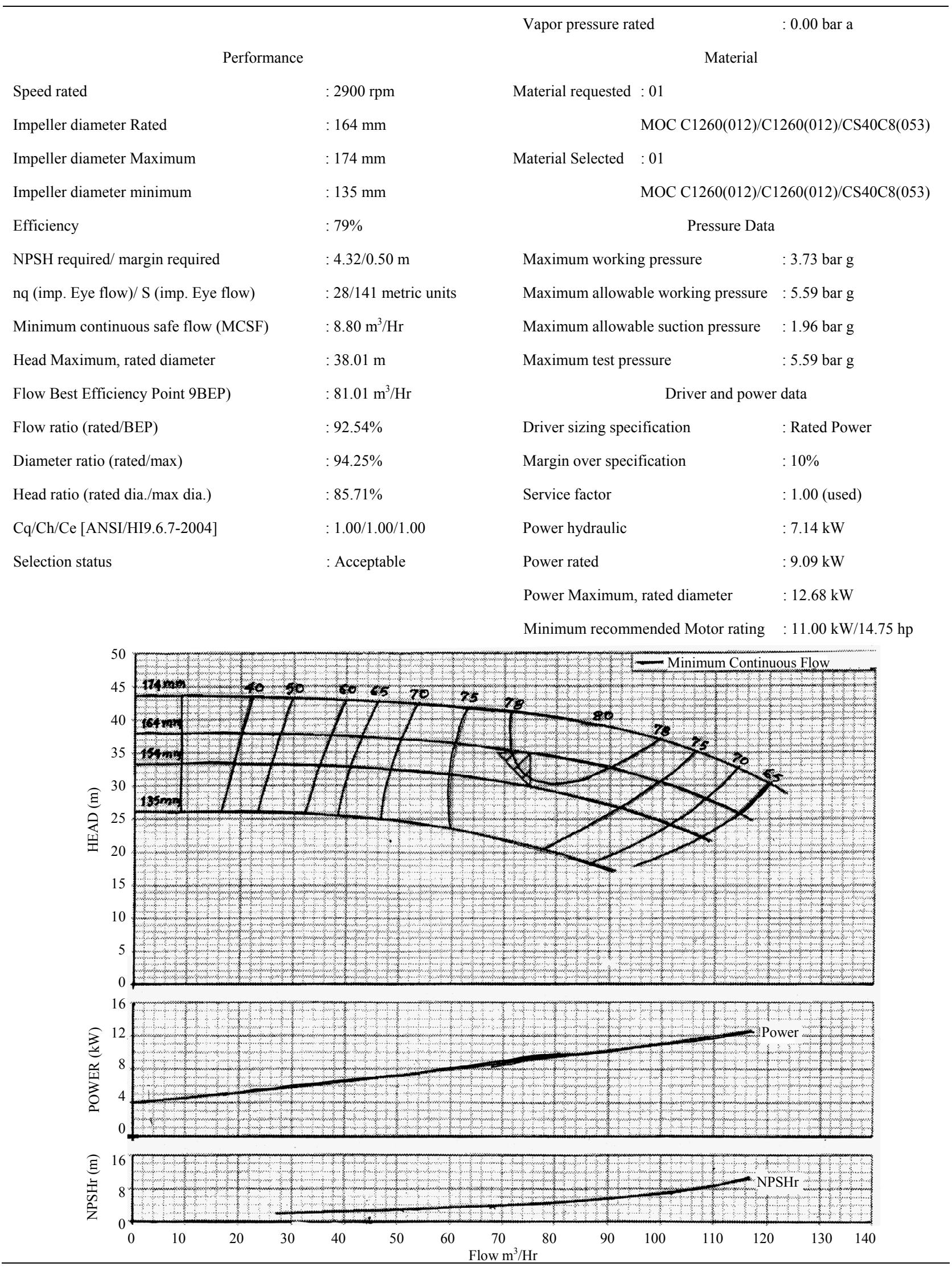

